\title{
The Economic Burden of Traumatic Brain Injury Due to Fatal Traffic Accidents in Shahid Rajaei Trauma Hospital, Shiraz, Iran
}

\author{
Zahra Kavosi ${ }^{1}$; Abdosaleh Jafari ${ }^{2}$; Nahid Hatam ${ }^{3}$; Meysam Enaami ${ }^{4, *}$ \\ ${ }^{1}$ Social Determinants of Health Research Center, School of Management and Information Sciences, Shiraz University of Medical Sciences, Shiraz, IR Iran \\ ${ }^{2}$ Health Economics Department, School of Management and Medical Information, Shiraz University of Medical Sciences, Shiraz, IR Iran \\ ${ }^{3}$ School of Management and Medical Information, Shiraz University of Medical Sciences, Shiraz, IR Iran \\ ${ }^{4}$ Student Research Committee, School of Management and Medical Information, Shiraz University of Medical Sciences, Shiraz, IR Iran \\ *Corresponding author: Meysam Enaami, Student Research Committee, School of Management and Medical Information, Shiraz University of Medical Sciences, Shiraz, IR Iran. Tel: \\ +98-9377708002, E-mail: meysamenami@yahoo.com
}

Received: August 20, 2014; Revised: February 13, 2015; Accepted: February 17, 2015

\begin{abstract}
Background:Traumatic Brain Injuries (TBIs) as a result of traffic accidents are one of the major causes of deaths, which lead to the loss of individuals' productive and working years of life.

Objectives: This study aimed to calculate the economic burden of traumatic brain injuries in fatal crashes at Shahid Rajaei Trauma Hospital, Shiraz, Iran for a period of five years.

Patients and Methods: In this descriptive, cross-sectional study the population included people who had died as a result of TBIs during 2009 to 2013 in Shiraz Shahid Rajaei Trauma Hospital. Cost and demographic data were obtained from the participants' medical records using data gathering forms, and some other information was also collected via telephone calls to the victims' families. Economic burden of TBIs due to traffic accidents, which led to death, was estimated using the human capital as direct costs of treatment, and the number of potential years of life lost and lost productivity as indirect costs.

Results: Deaths resulting from TBIs due to traffic accidents in Shiraz imposed 6.2 billion Rials (511000 USD) of hospital costs, 6390 potential years of life lost, and 506 billion Rials (20 million USD) of productivity lost. In the present study, the mean age of the individuals who died was $38.4 \pm 19.41$ and the productivity lost per capita was 1.8 billion Rials (73000 USD).

Conclusions: The findings of this study indicated that the economic burden of TBIs was high in fatal accidents in Fars Province so that it was equivalent to $0.00011 \%$ of Iran's Gross Domestic Product(GDP) in 2013. Therefore, more attention has to be paid to the rules to prevent the fatal accidents.
\end{abstract}

Keywords: Economic Burden; Potential Years of Life Lost (PYLL); Productivity Lost; Traffic Accidents; Traumatic Brain Injury

\section{Background}

Nowadays, progress in medical science and technology has significantly reduced mortality caused by infectious diseases. On the other hand, mortality due to accidents, especially car accidents, has increased (1). A survey conducted by the World Health Organization (WHO) revealed that about 5.3 million people die in accidents every year (2). Around the globe, deaths and injuries due to car accidents have the highest rate of deaths caused by unintentional injuries, and annually, they lead to the death of about 2.1 million people and injuries of 50 million people in the world (3).

Most car accidents occur in developing countries (4). Studies have shown that $75 \%$ of the one million people killed in road accidents were living in developing countries and half of them occurred in Asia, mainly in South Asia (5). According to the global burden of diseases, deaths caused by traffic accidents will be ranked as the sixth leading cause of death in the world by 2020; besides, traffic accidents will become the third cause of life years lost and years spent with disability. In addi- tion, in countries with low or medium income, traffic accidents will become the second leading causes of life years lost. The rate of death from traffic accidents will be increase to $80 \%$ in countries with low and medium income while in high-income countries; this rate will be reduced by up to $30 \%$ (6). Regarding road accidents, Iran is one of the top ranked countries in the world, and the number of deaths from road accidents has reached 30 in one thousand deaths (7). Most of these people are young, usually 20 to 30 years old (8). Traumatic brain injury as one of the causes of death and disability throughout the world is defined as damage to the brain that causes impairment and disability, often in the form of dramatic loss of power, independence, productivity and income potential (9). It is estimated that annually, 1.5 million people die after traumatic brain injury and millions of people require emergency treatment after this injury. Severity and mechanism of brain injury determine the resulting mortality and disability. However, an undesirable outcome (death, vegeta-

Copyright (c) 2015, Kashan University of Medical Sciences. This is an open-access article distributed under the terms of the Creative Commons Attribution-NonCommercial 4.0 International License (http://creativecommons.org/licenses/by-nc/4.0/) which permits copy and redistribute the material just in noncommercial usages, provided the original work is properly cited. 
tive coma and severe disabilities) following TBIs might reach over $20 \%(10,11)$. Moreover, the total lost years due to accidents are more than those caused by any other causes of death, and these lost years lead to $15 \%$ of the world's total wasted lives (4).

Although Iranian mass media report that casualties of traffic accidents are increasing, no accurate statistics about brain trauma are available. Brain injuries are important and have a high prevalence rate; nevertheless, their direct and indirect costs cannot be easily assessed. As a result, there is still no clear, integrated strategy to deal with and treat brain injuries, particularly mild injuries. Furthermore, the rate of injury incidence is unknown and this has an important role in estimating the cost of treatment $(12,13)$. This study aimed to calculate the economic burden of traffic accidents leading to death as a result of trauma brain injuries, including total direct and indirect costs, at Shiraz Shahid Rajaei Trauma Hospital, during a five-year period.

\section{Objectives}

Using the human capital approach that deals with hidden costs or opportunity costs of lost sources, this study aimed:

To calculate direct treatment costs spent on people who died of TBIs.

To estimate potential years of life lost and productivity lost by individuals who died, from the second half of 2009 to early 2013 at Shiraz Shahid Rajaei trauma hospital.

\section{Patients and Methods}

This was an economic evaluation of cost-outcome description, which was carried out as a retrospective cross-sectional research in 2013. The study population included all patients who had died as a result of brain injuries due to traffic accidents in Shiraz Shahid Rajaei Trauma Hospital from the second half of 2009 to early 2013. The primary costs, lost lives and lost production value were measured in these people from the viewpoint of the society. Direct costs associated with TBIs included direct treatment costs while indirect costs included the loss of income or lost production imposed to the society. Lost life due to premature death by TBIs was considered as a social cost, and a direct cost imposed to the society in the form of the number of potential lost years. In this study, we used the SPSS software version 19 for statistical analysis and Microsoft Office Excel for years of lost life and productivity lost calculations. For statistical analysis, independent samples t-test was used for comparing means of quantitative variables in two groups, one way analysis of variance (ANOVA) for comparing means of quantitative variable in more than two groups, and chi-square test according to normal variables for comparing frequency of qualitative variables in the two populations.

\subsection{Data Sources}

First of all, the types of required data as well as the hospital costs were determined. In order to collect the required data, we used two methods: firstly we performed a review of the patients in order to extract the cost data and the information of those who had died, including demographic data (age, sex, marital status, place of residence, patient's education, occupation and patient's insurance type). Secondly, we carried out phone call interviews with their family members to complete the data, especially about the patient's education and occupation. Regarding the macro approach of the present study, the economic burden was calculated as the total direct and indirect costs. We used the following methods to estimate the direct and indirect costs.

\subsection{Hospital Costs}

In this study, hospital costs referred to hospitalization, hoteling and medical costs including medicine, operating room, physician visits, radiology, physiotherapy, laboratory, ambulance and other fees recorded in hospital bills.

\subsection{Funeral Costs}

In order to estimate the funeral costs (14), the funeral costs paid to the families of those who had died, by social insurance organizations (15) were used. According to previously mentioned studies, the average funeral cost was 5 million IRR for each person who had died within the years of conducting this research. Hence, the total cost was estimated by multiplying the number of people who had died by the funeral-related fees.

\subsection{Potential Years of Life Lost}

The Standard Expected Years of Life Lost (SEYLL) was used to calculate the lost years due to premature death. In this method, the standard life expectancy is used at any age to estimate the lost years at that age. The total lost years for each age group was estimated by considering $3 \%$ discount rate and using the following formula $(16,17)$ :

$$
\mathrm{YLL}=\frac{\mathrm{NC} e^{(\mathrm{ra})}}{(\beta+r)^{2}\left[e^{(-\beta+r)(L+a)}[-(\beta+r)(L+a)-1]-e^{-(\beta+r)} a[-(\beta+r) a-1]\right]}
$$

In which $\mathrm{N}=$ the number of people who had died for a given age and gender; $\mathrm{L}=$ standard life expectancy of people who had died at the same age and sex; $\mathrm{R}=$ discount rate $(3 \%) ; \beta=$ contract rate for calculating age value $(0.04) ; \mathrm{C}=$ constant 0.1658 .

\subsection{Costs of Potential Productivity Lost}

Per capita Gross Domestic Product was used to calculate the costs of potential productivity lost, as shown by the formula below (14):

Potential production lost by the people who had died = 
Kavosi Z et al.

$$
\left[\sum \mathrm{W} \frac{(1+g)^{i}}{(1+r)^{i}}\right]
$$

$\mathrm{R}=$ discount rate $(0.05)(14) ; \mathrm{i}=$ average number of years lost due to fatal accidents (the average age of the people who had died minus life expectancy in 2013); $\mathrm{W}=$ the GDP per capita; $g=$ economic growth rate (3.7\%, mean economic growth in the past 30 years).

In this study the mean age of people who had died within 2009 to 2013 was 34, 37, 41, 44 and 36, respectively and life expectancy in Iran was 74 (18). Therefore, the average number of lost years for each death was calculated separately for each year (for example for 2013, 74-36 = 38). According to the World Bank database, the average GDP per capita was 88 million IRR (3552 USD) in 2013 (18).

\section{Results}

During 2009-2013, TBIs from traffic accidents were the underlying causes of 279 deaths at Shiraz Shahid Rajaei Trauma Hospital, amongst which 240 (86\%) were male and 197 (70.6\%) were married. The mean age of those who had died during this period was 38.4 and most deaths had occurred in the age group of $15-29(117=41.9 \%)$. The time of death in 83 cases (29.7\%) was before 24 hours. All individuals who had died, had been hospitalized for 2544 days in total, before dying and the average hospitalization period was nine days for each person. Most cases (147 people or 52.7\%) died in the Intensive Care Unit (ICU). Furthermore, $72 \%$ of deaths (201 patients) had occurred as a result of cerebral hemorrhage while the cause of death in eight people was skull fracture and in 70 patients (25\%) it was brain trauma. Regarding the underlying causes of injuries, the victims died as a result of car accidents (128 cases, $45.7 \%$ ), crashes of motorcycles with cars (91 cases, $32.5 \%$ ), motorcycle accidents (48 cases, $17.1 \%$ ) and pedestrian accidents (12 cases, 4.3\%). Among all 279 individuals who died, 250 people (89.6\%) used free treatment under article 92 of the Fourth Development Plan or they paid only a small part of the costs. Most of the deaths in Shiraz $(n=23)$ had occurred in district 5.

\subsection{Hospital and Funeral Costs}

Reviewing hospital records of patients who died in the accidents showed that the total costs of hospitalization, hoteling and treatment were 6273 million IRR (253300 USD), $98.9 \%$ of which was paid by the government according to article 92 of the Fourth Development Plan. According to this article, people who are injured in road accidents must be treated in hospitals free of charge. The total funeral cost was 1395 million IRR (56300 USD) and average hospital cost was 22 million IRR ( 888 USD) for each patient. Most hospital costs (63.3\%) were related to hospitalization costs including the cost of ICU, public bed and treatment (4008 million IRR, 161800 USD) (Table 1).

The hospital costs did not have a significant relationship with age, sex, marital status, type of insurance, occupation, education, time of death (before or after 24 hours), and the main and the underlying causes of death yet they had a significant relationship with location of residence (Shiraz, other cities of Fars Province, and outside of Shiraz) and duration of inhabitancy (Table 2).

Table 1. The Average Cost of Hospital Services for People With Brain Injury who Died as a Result of Traffic Accidents

\begin{tabular}{lccc}
\hline \multirow{2}{*}{ Costs } & \multicolumn{3}{c}{ Fee } \\
\cline { 2 - 4 } & Million IRR & USD & Percent of Total \\
\hline Hospitalization & 4008 & 161808 & 63 \\
Hoteling & 53 & 2139 & 1 \\
Operating Room & 438 & 17682 & 7 \\
Radiology & 169 & 6822 & 3 \\
medicine & 1098 & 44327 & 17 \\
Physiotherapy & 25 & 1009 & 0.5 \\
Laboratory & 207 & 8356 & 4 \\
Visit & 170 & 6863 & 2.7 \\
Other & 111 & 4481 & 1.8 \\
Total & 6279 & 253487 & 100 \\
\hline
\end{tabular}

Table 2. The Relationship Between Hospital Expenditure and Demographic Data of Individuals who Died ${ }^{\text {a }}$

\begin{tabular}{lcc}
\hline Demographic Characteristics & No. $\%)$ & Hospital Cost, IRR(USD) \\
\hline Duration of hospitalization & $110(39.4)$ & P Value \\
\hline day and less & $148(53)$ & $21168661.6 \pm 16778034(854 \pm 677)$ \\
\hline Up to 1 month & $16(5.7)$ & $36723420.4 \pm 24384510.3(1482 \pm 984)$ \\
\hline Up to 2 months & $5(1.8)$ & $51890539.2 \pm 19011247.5(2094 \pm 767)$ \\
\hline More than 2 months & & $17213466.2 \pm 13209139.7(694 \pm 533)$ \\
\hline Location of residence & $135(48.4)$ & $23184231.8 \pm 18086041.3,(935 \pm 730)$ \\
\hline Shiraz City & $103(36.9)$ & $26010033.2 \pm 22246331.7(1050 \pm 898)$ \\
\hline Other cities & $41(14.7)$ & 0.001 \\
\hline Out of Fars Province & & \\
\hline
\end{tabular}

\footnotetext{
a Data are presented as No. (\%) and Mean \pm SD.
} 
Kavosi Z et al.

\subsection{Life Lost Due to Premature Death}

The number of lost years as an indirect social cost was 6390.57 years for all people who died of TBIs during the study years in Shiraz Shahid Rajaei Trauma Hospital. This loss of years was 5725.63 for men and 664.94 for women of all ages. The most lost years were among 15-29 (117 death cases and 3954.55 years lost) and 30-44 (61 deaths and 1515.86 years lost) age groups, respectively. Amongst men, the greatest number of lost years was seen in the two above-mentioned age groups (102 death cases and 3447.56 lost years in the 15-29 age group and 53 death cases with 1317.06 lost years in 30-44 age group) while in women most death cases and, consequently, the greatest number of lost years (15 deaths and 378.62 lost years) were seen in the 15-29 age group.

\subsection{Potential Productivity Lost Due to Death}

Potential productivity lost was 1816 million IRR (73300 USD) for each person who died and 506770 million IRR (20 million USD) overall during 2009-2013. The potential productivity lost and the years of life lost are presented in the Table 3.

\section{Discussion}

This study indicated that the total estimated costs imposed by brain trauma deaths resulting from accidents were 513 billion Rials (20.7 million USD) during 2009 to $2013,98 \%$ of which was related to lost productivity (indirect costs) and $2 \%$ related to direct medical expenses at Shiraz Shahid Rajaei trauma hospital. This hospital is a center for patients with injuries (trauma injuries) in Fars Province and Shiraz City. According to WHO's estimation, the cost of road accidents is $1 \%$ of the GDP in low-income countries, while in medium- and high-income countries this cost can reach $1.5 \%$ and $2.0 \%$ of GDP, respectively (5). Although this was a local study, the total imposed cost was nearly $0.00011 \%$ of Iran's GDP in 2013. This reduction of GDP would impose considerable pressure on the economy of a growing country like Iran. In two other studies $(9,19)$, the lost revenue was considerable compared to
GDP with regards to the number of premature deaths. In the present study, the total direct medical cost (hospital costs) during 2009 to 2013 was 6273 million IRR (253300 USD) and the average direct medical cost was 22 million IRR (888 USD) for each individual who died regardless of the funeral expenses. The total direct costs were reported to be 2952 USD by al-Masaeid et al. (jordan) (20) and 6948 USD by study of Kayani et al. (9) during 2001-2005 per individual who died. In a study by Chen et al. (21) in Canada, $46 \%$ to $65 \%$ of direct medical costs were associated with acute and essential cares. Likewise, in the present study $63 \%$ of the total direct medical costs were related to hospitalization services and special care. Health care costs associated with TBIs might be catastrophic for households. In a study from Vietnam, $84 \%$ of TBIs patients' families were faced with catastrophic costs of health care services (22). In Iran, however, the implementation of article 92 of Iran's Fourth Development Plan seems to be effective in reducing the patients' out of pocket expenses; this can help the health system reach the goal of being fair in financial contribution. However, it is worth mentioning that from the viewpoint of the societies, this cost is a burden on the health system and the question is whether these costs, especially indirect ones, are repairable. The present study showed that the average life lost was 46 years per individual, which was higher than that of other studies $(9,14)$. This confirms that TBIs-related deaths occurred in younger individuals and a total of 6390.57 lost years were estimated as a result of premature deaths. Other studies have also reported a large number of life years lost due to accidents. For example, study of Kayani et al. the number of life years lost due to premature deaths was 48501 , representing a social loss as a result of premature death of 1358 people and a decrease in productivity (9). The mean age of the individuals who died was 38.4 with a median of 32 years and standard deviation of 19.41. This implies that a high percentage of deaths occur at a young age due to traffic accidents and, therefore, more years are lost. In all these studies, higher indirect costs were imposed on societies by means of losing more potential productivity. As estimated in this study, the lost productivity value was 73 thousand USD

\begin{tabular}{|c|c|c|c|c|c|}
\hline Year & 2009 & 2010 & 2011 & 2012 & 2013 \\
\hline Deaths & 38 & 102 & 77 & 34 & 28 \\
\hline \multicolumn{6}{|l|}{ Lost Years } \\
\hline Value & 996 & 2444 & 1664.5 & 678 & 608 \\
\hline Change, \% & & & -31.9 & -59.2 & \\
\hline \multicolumn{6}{|l|}{ Potential productivity lost } \\
\hline Value, Million IRR (Million USD) & $73675(2.9)$ & $189820(7.6)$ & $134377(5.4)$ & $56040(2.2)$ & $52857(2.1)$ \\
\hline Change, \% & & & -29.2 & -58 & \\
\hline
\end{tabular}

${ }^{a}$ As the study population included patients from the second half of 2009 to early 2013 and data of 2009 and 2013 were not complete, thus changes for these years were not calculated. 
per death case. In other studies done in Iran, this value ranged from 43 thousand USD per death (14) and 133 thousand USD per death resulting from job accidents (19) to and 326 thousand USD in the study of Kayani et al. (9). It is obvious that the prevention and reduction of traffic accidents are a matter beyond the scope of the health system; however, to play its role as a trustee, the health system is required to pay special attention to those who contribute to health outside the health sector in order to prevent traffic accident injuries and deaths (23). It is often believed that the ministry of health can play an important role by providing timely prehospital emergency services and ultimately medical and rehabilitation services as it has been proved that appropriate prehospital services and the availability of trauma centers after the accident are the key to the reduction TBIs-related deaths (24). Meanwhile, the health system has to work effectively in order to coordinate with other effective sectors to prevent traffic accidents. Evidence suggests that educating people and establishing driving regulations such as the use of helmets for motorcyclists, the use of seat belts for drivers, as well as improving vehicles and road safety are among effective factors in reducing traffic accidents and severe head injuries (25). In one study, Rezaei et al. clarified that head injury severity is the most important factor in the deterioration of cognitive functioning and general health and even has an important role in the incidence of mental disorders and other psychoneurological problems and disabilities in TBIs patients (26). In this study, there seemed to be a significant relationship between the total costs and the location of residence and duration of inhabitancy of the person who died. Regarding duration of inhabitancy, the difference in average costs was due to prolonged hospitalization and high costs of special care during hospitalization. Furthermore, regarding the place of residence of the person who died, difference in average costs could be due to differences in severity of the accidents so that people with more severe injuries had died earlier and it had not been possible for them to be hospitalized at the ICU with higher average costs. On the other hand, the average costs were higher for injured patients who had been referred from other cities in Fars Province because they had stayed longer at the ICU; doing post hoc tests and determining the significance of the relationship between variables showed that their average costs were significantly higher compared to that of others. According to the results of this study, economic burden of deaths as a result of TBIs in traffic accidents of Shiraz is high and will increase significantly if we consider the costs of victims with minor injuries or the productivity lost in hospitalized patients.

Consequent to the report issued by WHO in 2002, particular attention was paid to fatal traffic accidents and life years lost as a result, so that the annual reduction of traffic fatalities by 10\% was inserted in Article 163 of the Islamic Republic of Iran's fifth development plan.
However, unfortunately, a high number of premature deaths still occur as a result of traffic accidents and this emphasizes the need to revise adopted policies. On one hand, reducing the number of accidents can improve the community's health status through the reduction of life years lost and years living with disabilities. On the other hand, reduction in the number of accidents might reduce imposed additional costs on the health system and the country's economy because accidents impose a high financial burden, directly or indirectly, through lost productivity years of life or reduction of people's productivity capacity. Using the experiences of other countries to deal with this problem can guide policy makers. Implementation of an advertising-educational plan namely Global Helmet Vaccine Initiative in Vietnam showed that the use of helmets by motorcyclists reduced the risk of death and damage to the head by up to $18 \%$ and $16 \%$, respectively (27). This evidence suggests that it is not necessary for policy makers to think of complicated and costly options; sometimes an inexpensive and simple intervention is much more effective than other interventions.

In this study, due to lack of a prehospital costs record system in the Iranian health system, these costs were not taken into consideration. In addition, we did not consider the costs associated with accidents, such as the costs of car damages mentioned by other studies, which might impose a high economic burden on the society. Furthermore, limiting the research population to those who died in accidents can cause lower estimation of the financial burden on the society (9).

\section{Acknowledgements}

The authors appreciate the medical record department of Shiraz Shahid Rajaei Trauma Hospital, Shiraz, Iran for their sincere cooperation in conducting this study. Also we thank Professor N. Shokrpour for her help with improving the language of this manuscript.

\section{Authors' Contributions}

Meysam by Al-Masaeid's Kavosi and Abdosaleh Jafari contributed to searching the literature, analyzing the results and its interpretation. Meysam Enaami, Zahra Kavosi, Abdosaleh Jafari and Nahid Hatam drafted the initial manuscript. Meysam Enaami, Zahra Kavosi, Abdosaleh Jafari and Nahid Hatam and the other co-authors answered the reviewer's remarks and recommendations. All authors read and approved the final manuscript.

\section{Funding/Supports}

This study was supported by Shiraz University of Medical Sciences (Grant No: 92-2823).

\section{References}

1. Dixey RA. 'Fatalism', accident causation and prevention: issues for health promotion from an exploratory study in a Yoruba town, Nigeria. Health Educ Res. 1999;14(2):197-208. 
2. WHO.. Handle Life with Care: Prevent Violence and Negligence.: World Health Organization; 1993.

3. Wang $\mathrm{CH}$, Tsay SL, Bond AE. Post-traumatic stress disorder, depression, anxiety and quality of life in patients with traffic-related injuries. J Adv Nurs. 2005;52(1):22-30.

4. Soori H, Naghavi M. Deaths from unintentional injuries in rural areas of the Islamic Republic of Iran. East Mediterr Health J 1999;5(1):55-60.

5. Peden M. World report on road traffic injury prevention.Geneva: World Health Organization; 2004.

6. Murray CJ, Lopez AD. Alternative projections of mortality and disability by cause 1990-2020: Global Burden of Disease Study. Lancet. 1997;349(9064):1498-504.

7. Akbari ME, Naghavi M, Soori H. Epidemiology of deaths from injuries in the Islamic Republic of Iran. East Mediterr Health J. 2006;12(3-4):382-90.

8. Sanaei-Zadeh H, Vahabi R, Nazparvar B, Amoei M. An epidemiological study and determination of causes of traffic accidentrelated deaths in Tehran, Iran (during 2000-2001). J Clin Forensic Med. 2002;9(2):74-7.

9. Kayani NA, Homan S, Yun S, Zhu BP. Health and economic burden of traumatic brain injury: Missouri, 2001-2005. Public Health Rep. 2009;124(4):551-60.

10. Bruns JJ, Hauser WA. The epidemiology of traumatic brain in jury: a review. Epilepsia. 2003;44 Suppl 10:2-10.

11. Fleminger S, Ponsford J. Long term outcome after traumatic brain injury. BMJ. 2005;331(7530):1419-20.

12. Af Geijerstam JL, Britton M, Marke LA. Mild head injury: observation or computed tomography? Economic aspects by literature review and decision analysis. Emerg Med J. 2004;21(1):54-8.

13. Bazarian JJ, McClung J, Cheng YT, Flesher W, Schneider SM. Emergency department management of mild traumatic brain injury in the USA. Emerg Med J. 2005;22(7):473-7.

14. Rezaei S, Arab M, Karami Matin B, Akbari Sari A. Extent, consequences and economic burden of road traffic crashes in Iran. $J$ Inj Violence Res. 2014;6(2):57-63.
15. Social Security Organization.. Terms of burial subsidy.Tehran: Iran's tamin ejtemaee organization; 2014

16. Ayatollahi ST, Hassanzadeh J, Ramezani AA. The burden of traffic accidents in South Khorasan province, Iran in 2005. Iran J Epidemiol. 2009;4(3):51-7.

17. Mathers C, Fat DM, Boerma JT. The global burden of disease: 2004 update.: World Health Organization; 2008.

18. The World Bank. Health.; 2014.

19. Karimi I, Zohour AR, Zokaie HR. Estimation of Human Cost of Occupational Injuries Leading to Death of Security insured populace. J Health Adm. 2004;7(15):22-7.

20. al-Masaeid HR, al-Mashakbeh AA, Qudah AM. Economic costs of traffic accidents in Jordan. Accid Anal Prev. 1999;31(4):347-57.

21. Chen A, Bushmeneva K, Zagorski B, Colantonio A, Parsons D, Wodchis WP. Direct cost associated with acquired brain injury in Ontario. BMC Neurol. 2012;12:76.

22. Hoang HT, Pham TL, Vo TT, Nguyen PK, Doran CM, Hill PS. The costs of traumatic brain injury due to motorcycle accidents in Hanoi, Vietnam. Cost Eff Resour Alloc. 2008;6:17.

23. Krug EG, Mercy JA, Dahlberg LL, Zwi AB. The world report on violence and health. Lancet. 2002;360(9339):1083-8.

24. Klemen P, Grmec S. Effect of pre-hospital advanced life support with rapid sequence intubation on outcome of severe traumatic brain injury. Acta Anaesthesiol Scand. 2006;50(10):1250-4

25. Soori H, Nasermoadeli A, Movahedi M, Mehmandar MR, Hatam Abady HR, Rezazadeh-Azari M, et al. The effect of mandatory seat belt use legislations on mortalities from road traffic injuries in Iran. Hakim Res J. 2009;12(1):48-54.

26. Rezaei S, Asgari K, Yousefzadeh S, Moosavi HA, Kazemnejad E. Effects of neurosurgical treatment and severity of head injury on cognitive functioning, general health and incidence of mental disorders in patients with traumatic brain injury. Arch Trauma Res. 2012;1(3):93-100.

27. Passmore JW, Nguyen LH, Nguyen NP, Olive JM. The formulation and implementation of a national helmet law: a case study from Viet Nam. Bull World Health Organ. 2010;88(10):783-7. 